\title{
Towards a Framework for Establishing Children's Toys Safety Policy in ASEAN
}

Rahmah Ismail, Wan Amir Azlan Wan Haniff, Suzanna Mohamed Isa, Rozlinda Mohamed Fadzil, Syed Sagoff AISagoff, Kartini Aboo Talib @ Khalid

To Link this Article: http://dx.doi.org/10.6007/IJARBSS/v11-i3/8812

DOI:10.6007/IJARBSS/v11-i3/8812

Received: 08 January 2021, Revised: 03 February 2021, Accepted: 28 February 2021

Published Online: 16 March 2021

In-Text Citation: (Ismail et al., 2021)

To Cite this Article: Ismail, R., Haniff, W. A. A. W., Isa, S. M., Fadzil, R. M., AlSagoff, S. S., \& Khalid, K. A. T. @. (2021). Towards a Framework for Establishing Children's Toys Safety Policy in ASEAN. International Journal of Academic Research in Business and Social Sciences, 11(3), 892-904.

Copyright: (c) 2021 The Author(s)

Published by Human Resource Management Academic Research Society (www.hrmars.com) This article is published under the Creative Commons Attribution (CC BY 4.0) license. Anyone may reproduce, distribute, translate and create derivative works of this article (for both commercial and non-commercial purposes), subject to full attribution to the original publication and authors. The full terms of this license may be seen at: http://creativecommons.org/licences/by/4.0/legalcode

Vol. 11, No. 3, 2021, Pg. 892 - 904

Full Terms \& Conditions of access and use can be found at http://hrmars.com/index.php/pages/detail/publication-ethics 


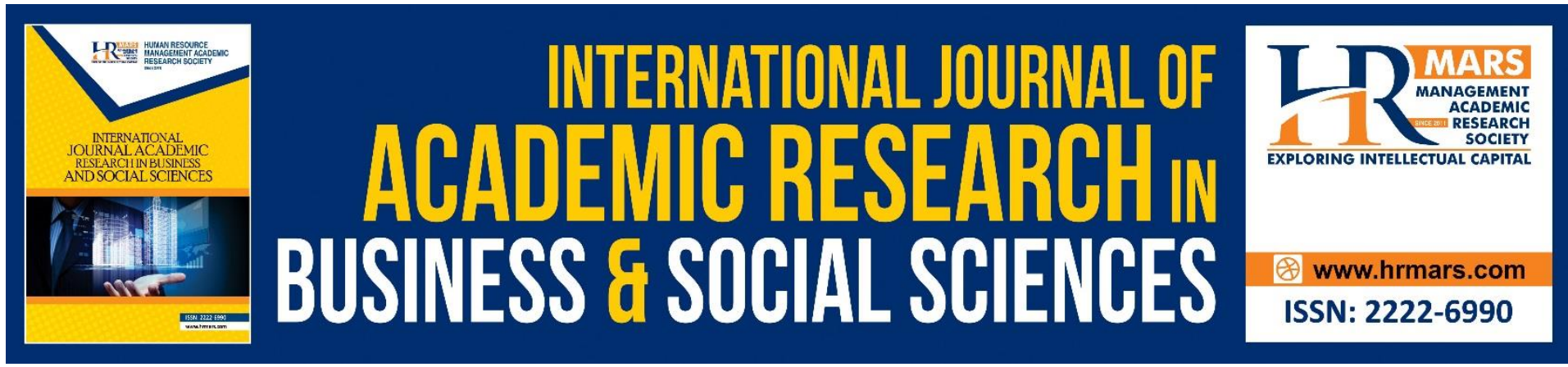

\title{
Towards a Framework for Establishing Children's Toys Safety Policy in ASEAN
}

\author{
Rahmah Ismail a, Wan Amir Azlan Wan Haniff b, Suzanna \\ Mohamed Isac, Rozlinda Mohamed Fadzild, Syed Sagoff \\ AlSagoff ${ }^{e}$, Kartini Aboo Talib @ Khalid
}

${ }^{a}$ Associate Professor, Ph.D, Faculty of Law, National University of Malaysia, 43600 UKM, Bangi, Selangor, Malaysia, ${ }^{b}$ Senior Lecturer, Department of Law, Universiti Teknologi Mara Cawangan Johor, 85000, Segamat, Johor, Malaysia, ' Associate Professor, Ph.D, Faculty of Law, National University of Malaysia, 43600 UKM, Bangi, Selangor, Malaysia, d Senior Lecturer, Faculty of Law, National University of Malaysia, 43600 UKM, Bangi, Selangor, Malaysia, e Ph.D, Former Senior Officer, ASEAN Secretariat, Jakarta, Indonesia, ${ }^{f}$ Associate Professor, Ph.D, Institute of Ethnic Studies, National University of Malaysia, 43600 UKM, Bangi, Selangor, Malaysia

Email: irahmah@ukm.edu.my,wamirazlan@uitm.edu.my, zie@ukm.edu.my, leenda@ukm.edu.my, alsegaff@hotmail.com, kartinikhalid@gmail.com

\begin{abstract}
The use of toys over decades has become more extrinsic and has extended from a mere play thing to a tool used for educational development including vulnerable categories of children with special needs. The increase in demand has also brings with it an alarming number of incidents and accidents connected with children's toy products worldwide particularly within European Union and United States, which largely imports the said products from Association of Southeast Asian Nations (ASEAN). To make matters worse, there is an absence of comprehensive children's toys safety legislations within several ASEAN Member States. Therefore, there is an urgent call for the establishment of Children's Toys Safety Policy in ASEAN in order to enhance the safety of children's toys and facilitate trade. Hence, for the purpose of proposing components of Children's Toys Safety Policy in ASEAN, this qualitative research utilised data from European Union Toy Safety Directives (Directive 2009/48/EC), New Zealand ISO 10377:2017, ASEAN Food Safety Policy and ASEAN Good Regulatory Practice in light of potential harmonisation mechanisms. The finding shows that there are four (4) principles suggested in the proposed Policy, which are promoting toy safety culture; toy safety commitment and responsibility; systematic toy safety framework; and responsibility of ASEAN Member States.
\end{abstract}

Keywords: Manufacturers, Importers, Distributors, ASEAN, Legislations, Harmonisation, Policy 


\section{Introduction}

Statista (2019) revealed that toy industries worldwide raked an income of USD90.4 billion from its sales in 2018, while in the United States (US), the largest consumable for toys grew to USD20.7 billion in 2017 (NPD Group, 2018). Further, according to Ismail et al. (2020), ASEAN has become the third largest exporter of toy products in the world after China and Europe accounting for $€ 864.09$ million with exported toy products worth $€ 255.36$ million to the European Union (EU) in 2011. Latest figures in numerous ASEAN Member States (AMS) also reveals increasing number of export of toy products to the European Union and around the world. For example, in 2016, the exportation of children's toys from Thailand attained more than USD200 million (Asia Toy \& Play Association, 2017), whereas Vietnam's recorded USD235.7 million in the first quarter of 2017 for both sports equipment and children's toys product ("Ninety-Five Percent of Vietnam-Made Toys Exported", 2017). Despite the increasing number of demand, there is also an alarming number of incidents and accidents connected with children's toy products worldwide. Every year, nearly 60,000 cases were reported in Europe to the extent that the children's toy products were ranked 4th in the "Infant or child products" involved in child injuries (under 5 years of age) after swing, sliding board, and high chair (Eurosafe, 2013).

As Afida, Elistina \& Suhaili (2014) put it, unlike adult, children are vulnerable and at higher risk of hurting themselves. They are incapable of self-assessing the toys that they are playing (Howells and Weatherill, 2005). Hence, it depends on their parents good judgement to examine every security aspect of such toys before passing it to their child. Nevertheless, it will be difficult when it involves certain feature such as chemical aspect as not everyone has such expertise.

It is a well-known fact that there are many unsafe toys marketed in ASEAN Member States (AMS) In Malaysia alone, a test carried by Malaysian Association of Standards Users and Greenfinite Sdn Bhd in 2016 has found that half of the tested toys sold in supermarket were found to have heavy metals and chemical more than the allowable limit (Fong, 2016). Besides that, Selangor Domestic Trade and Consumer Affairs has seized 4,137 toys for noncompliance with safety standards (Bernama, 2018). Meanwhile, in Thailand, Decharat et al. (2013) examined lead level in 100 children's plastic toys imported from China and found that $13 \%$ of the tested samples had lead level greater than the European Union permissible limit. In Singapore, ten magnetic toys, including magnetic building blocks and balls commonly known as Buckyballs, were tested and found to be unsafe for children (CNA, 2019). The result of the tests carried out in Vietnam also very alarming especially for children's toys product name 'The Chinese Balloon' which, upon evaluation, contained phthalate more than the permitted international standard level (Uyen, 2017). Unfortunately, other AMS do not have data on unsafe toys. However, that does not mean those countries are free from unsafe toys. Unfortunately, other AMS do not have data on unsafe toys. However, thatdoes not mean those countries are free from unsafe toys.

To add insult to injury, Ismail (2020) found that not all AMS have specific legislations on toy safety product. Only Malaysia, Indonesia and Philippines have specific legislations on toy safety. Malaysia for instance regulates the safety of toys through Consumer Protection (Safety Standards for Toys) Regulations 2009. Under this regulation children's toys that are marketed in Malaysia must comply with mandatory standards prescribed under the regulation. Indonesia has enacted Toy Safety Regulations and Standards in 2013. Under this legislation, Indonesia has prescribed safety standards for toys. Philippines also has enacted 
specific act for toys. The act is Toy and Game Safety Labelling Act 2013. The Act requires all games and toys that are locally manufactured, distributed, donated, imported and sold in the Philippines have to mark with or accompanied by clear safety warnings.

Nonetheless, despite the absence of specific legislations on toy safety, they still have their own general consumer protection legislation. Still, the writers believe it is insufficient to protect the children. Specific law or legislation are still needed to protect them from unsafe toys. Haniff, et al. (2020) supported the idea and highlighted the need for ASEAN to ratify and implement adequate national and regional legislations and regulations specifically for import, export, manufacturing, adoption and sale of children toys for the purpose of averting the accessibility of hazardous children toys product in the market. Hencethe writers assert that it is high time for ASEAN to have Children's Toy Safety Policy.

\section{Research Objective}

The objective of this paper is to suggest the components of Children's Toy Safety Policy in ASEAN. This objective is in line with the ASEAN Strategic Action Plan for Consumer Protection (ASAPCP) which includes but not limited to build upon the ASEAN Committee on Consumer Protection work on consumer protection and provides ASEAN's strategy for consumer policy over the next ten years (2016-2025) (ASAPCP, nd). It is worth mentioning that the establishment of ASAPCP was based on the ratification of ASEAN Economic Community (AEC) Blueprint 2016-2025 which is a binding declaration of obligations to all associate countries (AEC Blueprint, 2016).

\section{Research Methodology}

Haniff et al. (2020) has proposed the approach of non-treaty harmonisation mechanisms to overcome the inadequacy of safety standards on children's toys within AMS. Meaning, each AMS with close political and trade relationship may institute a framework for Mutual Recognition Agreements to regulate the safety policy of children's toys. This method is not novel as it has been carried out before in 2003 in cosmetics regulation area when AMS developed a structure for Mutual Recognition Agreements by ratifying the Agreement on the ASEAN Harmonized Cosmetics Regulatory Scheme (ASEAN Cosmetic Documents, 2018). This was anticipated as a preliminary measure towards enforcing a harmonised 'ASEAN Cosmetics Directive' regime by 2008. The directive is in accordance with the EU's 1976 Cosmetic Directive and has been executed in all AMS since 2013. Besides, Ismail et al. (2019) pointed out that pursuant to Article 4(1) of the ASEAN Cosmetic Directive, AMS should adopt Cosmetic Ingredient Listings of the EU Cosmetic Directive 76/768/EEC comprising the most recent amendments.

Hence, for the purpose of proposing components of Children's Toy Safety Policy in ASEAN, this qualitative research utilised data from European Union Toy Safety Directives (Directive 2009/48/EC), New Zealand ISO 10377:2017, ASEAN Food Safety Policy and ASEAN Good Regulatory Practice in light of potential harmonisation mechanisms. The data collected is then analysed using content analysis. Content analysis is a research method that is adopted to analyse legal provisions, ministries' decisions, academic books, contracts and decided cases. Most of the data collected are statutes, books and articles. 


\section{Literature Review}

Protecting the consumers' interests, particularly children, started in 1924 when the League of Nations had declared the Children's Rights Declaration. In the same year United Nations adopted this declaration, Human Rights Declaration was announced which consists of universal human values which apply to all human, including children (Talib Khalid, 2015). With increasing consumer demands, coupled with technological advancements, more toys will be produced and the hidden hazards that come with them are inevitable. Even though countless countries have some form of legislation in place, the injuries that it may pose by toys are still presence especially for imported toys from countries with lenient or no safety regulation at all.

In the US, an estimation of 256,700 toy-related injuries were recorded in 2013 in which nearly two thirds of these incidents happened to children below 15 years old, $69 \%$ to children below 12 years old and one thirds to children below than 5 years old (CPSC US, 2013). Plus, In EU alone, Eurosafe (2013) reported 57,000 cases of toy related injuries and 35,000 cases involving infants' articles. These figures indicate the need to have toy safety measures, and this is what happening today when standards developers are making an effort to harmonize available standards on the essential requirements and equivalency in order to ensure only children's toys that reach acceptable safety standards are allowed to be put onto store shelves. These attempts have further driven standards development into greater heights and ASEAN should not be left behind.

Apart from that, the Framework for Action based on 2030 Agenda (Transforming our world: The 2030 Agenda for Sustainable Development) (A/RES/70/1) adopted at United Nations (UN) Sustainable Development Summit on 25 September 2015, compliments one of the ASEAN Community Vision 2025 (2015) which is to promote high quality of life, equitable access to opportunities for all as well as supports and safeguards human rights of children. In other words, both visions are indivisible and interlinked. With over 17 Sustainable Development Goals and 169 targets covering an array of activities aimed at "win-win" cooperation, one of these goals support the development of ASEAN Toy Safety Policy which is Goal No. 3 regarding health and well-being for all, at every stage of life (United Nations, 2020).

In this sense, the writers believe that the operational guidelines stipulated under ASEAN Vision 2025 and UN 2030 Agenda support effort towards the Development of ASEAN Toy Safety Policy especially when the proposal fulfils both agendas collectively with no conflicting commitments (UN ESCAP, 2018). The writers are also of the view that one priority area which ASEAN 2016-2025 Strategic Action Plan should focus and pay close attention is the accessibility of safe toys for its children. Regardless of trade volume, the need to protect our next generation especially children have become crucial. Thus, the writers propose the establishment of Toy Safety Policy in ASEAN.

\section{Research Findings}

Based on the above discussion, the writers submit that ASEAN should establish their own Children's Toy Safety Policy. As mentioned above, in drafting the Policy, the writers have referred to the European Union Toy Safety Directives, New Zealand ISO 10377:2017, ASEAN Food Safety Policy and ASEAN Good Regulatory Practice. In this part, the writers are discussing 
the components of the proposed Children's Toy Safety Policy (Policy). It is proposed that this Policy will serve as a practical guide to the manufacturers in producing safe toys. This Policy aims to harmonise the regulatory requirements for the marketing of toys in ASEAN and the safety of toys for use in play by children of 14 years old and below. The objectives of the Policy are as follows:

- to provide a toy safety framework at ASEAN level;

- to improve level of safety, obligation and clarification on scope and principle on toy safety;

- to stimulate export and inward investment in ASEAN market;

- to enhance the standard and conformance of toy safety requirements to meet the present and future needs of ASEAN;

- to strengthen private sector participation in standard and conformance of toy safety requirements; and

- to build consumer confidence on toys placed in the ASEAN market.

There are 4 principles suggested in the proposed Policy. They are:

1. promoting toy safety culture;

2. toy safety commitment and responsibility;

3. systematic toy safety framework; and

4. responsibility of AMS.

\section{Principle 1: Promoting toy safety culture}

Producing safe toys shall be the main agenda of toy manufacturers. This agenda can be achieved if the safety of the children toy is integrated in the Organisation Management Plan which is approved and implemented by the top management of the organisation. The toy safety culture shall be inculcate in the organisation through the following measures:

1. the management shall give full commitment towards safety aspect:

2. the management shall design safety system (such as, safety policy, safety regulations or safety procedures); and

3. the management shall create effective communication in the organisation regarding toy safety.

\section{Principle 2: Toy safety commitment and responsibility}

Under this principle obligations are imposed on the manufacturers, importers, distributors and consumers. It is submitted that all persons in the distribution chain together with consumers have their roles to play in ensuring children's toy safety.

Obligation of manufacturers

The writers have proposed the following components to be inserted in the obligation of manufacturers:

a. Manufacturers shall undertake the commitment to design, manufacture and market only safe toys.

b. The manufacturers shall also ensure that all toys placed in the market have been designed and manufactured in accordance to an international accepted standard.

c. Manufacturers shall be responsible to carry out the necessary conformity procedures, draw up and keep all the necessary documents pertaining to compliance.

d. Manufacturers shall ensure that any changes in toy design or characteristics shall remain in conformity with the international accepted standard. 
e. Manufacturers shall ensure that their toys bear a type, batch, serial or model number or other element allowing their identification and the required conformity marking, or where the size and nature does not allow it, such required information is provided on the packaging or in a document accompanying the toy.

f. Manufacturers shall indicate their name, registered trade name or registered trade mark and the address at which they can be contacted on the toy, or where that is not possible, on its packaging or in a document accompanying the toy.

g. Manufacturers shall ensure the toy is accompanied by instructions and safety information in English and local language easily understood by consumers, (as determined by the Member State concerned.)

h. Manufacturers who consider or have reason to believe that a toy that they have placed in the market has not conformed to an international accepted standard, shall immediately take corrective measures necessary to bring the toy into conformity, to withdraw it or recall it, if appropriate.

i. Where the toy presents a risk, manufacturers shall carry out sample testing of marketed toys, investigate and document complaints, non-conforming toys and toy recalls; and immediately inform the competent national authorities of the Member State in which they were marketed and relevant distributors giving details, in particular to non-compliance and any corrective measures taken.

j. Manufacturers shall co-operate with relevant authorities as regards to any action taken to eliminate the risks posed by toys they have placed in the market.

The writers argue that by imposing these obligations on the manufactures will ensure the toy safety.

\section{Obligation of Importers}

Although importers are not involved in product manufacturing, there is still a need to impose the toy safety obligation on the importers. This is because before the importers agree to import any toys, they have to make sure that only safe toys are place on the market. Hence, the following obligations are imposed on the importers:

a. Importers shall undertake the commitment to place only safe toys in the market.

b. Importers shall ensure that the appropriate conformity assessment procedures and documents have been undertaken by the manufacturers before placing a toy in the market.

c. Importers shall ensure that the toy bears the required conformity marking and is accompanied by instructions and safety information in a English and local language understood by consumers, as determined by the Member State concerned.

d. Importers who consider or have reason to believe that a toy that is placed in the market has not conformed to an accepted international accepted standard shall not place the toy in the market until it has been brought to conformity. Where the toy presents a risk, the importer shall inform the manufacturer and market serveillance authorities.

e. Importers shall indicate their name, registered trade name or registered trade mark and the address at which they can be contacted on the toy, or where that is not possible, on its packaging or in a document accompanying the toy.

f. Importers shall be considered a manufacturer if they place a toy in the market under its name or trademark or modifies a toy already in the market in such a way the compliance with the international accredited system may be affected. 
g. Importers shall ensure the toy is accompanied by instructions and safety information in English and local language easily understood by consumers, as determined by the Member State concerned.

h. Importers shall ensure that, while a toy is under their responsibility, storage or transport conditions do not jeopardise its compliance with the international accreditation system.

i. Importers who consider or have reason to believe that a toy that they have placed in the market has not conformed to an international accepted standard, shall immediately take corrective measures necessary to bring the toy into conformity, to withdraw it or recall it, if appropriate.

j. Where the toy presents a risk, importers shall carry out sample testing of marketed toys, investigate and document complaints, non-conforming toys and toy recalls; and immediately inform the competent national authorities of the Member State in which they were marketed and relevant distributors giving details, in particular to noncompliance and any corrective measures taken.

k. Importers shall co-operate with relevant authorities as regards to any action taken to eliminate the risks posed by toys they have placed in the market.

I. Importers shall keep a copy of declaration of conformity to an international accepted standard and make such document available to market surveillance authorities upon request.

m. Importers shall, upon a reasoned request from a relevant national authority, provide all the information and documentation necessary to demonstrate conformity of a toy in English and local language easily understood by the authority. They shall co-operate with that authority as regards to any action taken to eliminate the risks posed by toys they have placed in the market.

\section{Obligation of Distributors}

Under the proposed Policy, the distributors shall have the following obligations:

a. Distributors shall undertake the commitment to place only safe toys in the market.

b. Distributors shall ensure that the appropriate conformity assessment procedures and documents have been undertaken by the manufacturers before placing a toy in the market.

c. Distributors shall ensure that the toy bears the required conformity marking and is accompanied by instructions and safety information in English and local language easily understood by consumers, as determined by the Member State concerned.

d. Distributors who consider or have reason to believe that a toy that placed in the market has not conformed to an international accepted standard shall not place the toy in the market until it has been brought to conformity. Where the toy presents a risk, the distributor shall inform the manufacturer, importer and market serveillance authorities.

e. Distributors shall be considered a manufacturer if they place a toy in the market under its name or trademark or modifies a toy already in the market in such a way the compliance with the international accepted standard may be affected.

f. Distributors shall ensure that, while a toy is under their responsibility, storage or transport conditions do not jeopardise its compliance with the international accepted standard. 
g. Distributors who consider or have reason to believe that a toy that they have placed in the market has not conformed to an international accepted standard shall immediately take corrective measures necessary to bring the toy into conformity, to withdraw it or recall it, if appropriate.

h. Where the toy presents a risk, distributors shall immediately inform the competent national authorities of the Member State in which they were marketed, giving details, in particular to non-compliance and any corrective measures taken.

i. Distributors shall co-operate with relevant authority as regards to any action taken to eliminate the risks posed by toys they have placed in the market.

j. Distributors shall keep a copy of declaration of conformity to an accepted standard and make such document available to market surveillance authorities upon request.

k. Distributors shall, upon a reasoned request from a relevant national authority, provide all the information and documentation necessary to demonstrate conformity of a toy in English and local language easily understood by the authority. They shall co-operate with relevant national authority as regards to any action taken to eliminate the risks posed by toys they have placed in the market.

\section{Obligation of Consumers}

Consumers are not involved in the manufacturing, importing and distributing process of toys nevertheless the consumers also have their roles in ensuring the safety of toys they bought. The following are their obligations:

a. Consumers shall ensure that toys bought are used in a reasonable manner.

b. Consumers shall ensure that they will adhere to all usage methods and warnings given by the manufacturers, importers and distributors in the accompanying instructions and safety information document.

\section{Principle 3: Systematic toy Safety Framework}

Under this principle, the writers divide toy safety framework in three stages:

1. Pre-production;

2. Production; and

3. Post production.

The reason why it is divided in such a way is because every stage has its own safety framework.

\section{Pre-production}

It is the responsibility of the manufacturer to ensure safety in product design, recognizing that design defects are highly preventable. The manufacturer must ensure that the product design has complied with international accepted standard or national standard.

\section{Production}

The toy manufacturer has the primary roles and responsibility for ensuring the safety of toy. The manufacturer shall establish and implement appropriate Good Manufacturing Practices (GMP). The GMP shall consist of quality monitoring and finished product testing. The roles and responsibilities of the manufacturers shall be exhibited in the following measures:

i. Safety in production

a. The manufacturer shall provide for Toy Safety Culture in the production process. 
b. The manufacturer shall put in place all the necessary aspects of toy safety, including training throughout all phases of its production process. The manufacturer should verify that its supply chain providers of raw materials, components, chemical contents and subassemblies have incorporated all the necessary aspects of product safety into their individual production practices.

c. The manufacturer should also follow industry's GMP during the production of toy.

ii. Conformity of toys: Warning, labelling, marking (International Accepted Standards)

a. Manufacturers shall ensure that toy they produce has adequate warning and marking on the label, packaging and instruction for use.

b. The manufacturer shall mark the warnings in a clearly visible, easily legible and understandable and accurate manner on the toy, on an affixed label or on the packaging and, if appropriate, on the instruction for use which accompany the toy. Small toy which are sold without packaging shall have appropriate warnings affixed to them. The warning shall be precede by the words 'Warning' or 'Warnings', as the case may be.

c. Labels should be in English and local language easily understood by consumers as determined by the member states concern.

iii. Conformity assessment: Testing, labelling and risk management

a. Manufacturer shall, before placing a toy on the market, carry out an analysis of the chemical, physical, mechanical, electrical, flammability, hygiene and radioactivity hazards that the toy may present, as well as an assessment of the potential exposure to such hazards.

Manufacturer shall establish Conformity Assessment Procedures to ensure that there is a consistency in pre-marketing product analysis.

\section{Post-production}

The basic principle of toy safety does not stop once products are marketed. The roles and responsibilities of toy manufacturers continue although the products been marketed. The followings are roles and responsibilities of the manufacturers at post-production stage:

a. The manufacturers have to establish Post-monitoring System.

b. The manufacturers have to establish Continual Improvement System in order to improvise the products.

c. The manufacturers have to establish Reliable Traceability System in order to trace unsafe toys.

\section{Principle 4: Responsibility of AMS}

In order to give effect to the Policy, the heads of AMS shall take the following measures:

a. Enacting laws - laws need to be enacted to give legal effect to the Policy. If the Policy is not incorporated in the laws, the Policy will remain as a soft law which does not have legal effect.

b. Strengthening and harmonization of national and regional toy safety system.

Consistency with ASEAN Trade in Goods Agreement (ATIGA) - ATIGA requires AMS to harmonise their national standard with international standards as a means of removing unnecessary trade barriers. 


\section{Conclusion}

Since AMS has become one of the biggest exporters of toy product in the world and has potential to develop the largest market in years ahead, the enhancement of toy safety development has never been more important. Hence, ASEAN should develop a directive or policy on toy safety by setting relevant documents as an example. Besides able to create appearance of single regulatory structure, this initiative may be able to provide the facilities for free movement of toy products around the world. Without a doubt, effective enforcement mechanism requires commitment from AMS. This is inter alia why EU able to create harmonise regulatory standards to protect consumers safety especially children who are considered as vulnerable group.

Further, in tandem with several ASEAN documents, the writers are of the opinion that the broad approach used by ASEAN in developing Mutual Recognition Agreements could be used as a yardstick to measure key objective behind the proposed ASEAN toy safety policy or directive. For instance, AEC Blueprint 2025 (2016) clearly specify the need for ASEAN in assuring smooth execution towards convergence of trade facilitative regimes among AMS as well as moving closer to the global best practices. The same Blueprint also stresses the importance of executing standards harmonisation, technical regulations, quality enhancement and efficiency in conformity assessment procedures, improved information exchange on rules, laws, as well as administrative processes among AMS. Hence, it is essential for AMS to promote positive values and attentive regulatory regimes through effective participation with private sector, ASEAN stakeholders and community-based organisations.

\section{Acknowledgment}

This paper is part of the findings of a research project FRGS/1/2017/SSI10/UKM/02/4

\section{References}

AEC Blueprint. (2016). Retrieved from https://www.asean.org/storage/2016/03/AECBP_2025r_FINAL.pdf [6 March 2021].

Afida, M., Elistina, A. B., \& Suhaili, O. (2014). Perlindungan Pengguna: Ke arah Memperkasakan Pengguna di Malaysia. Selangor: MACFEA Press.

ASAPCP. (nd). The ASEAN strategic action plan for consumer protection(ASAPCP) 20162025: meeting the challenges of a people-centered asean beyond 2015. Retrieved from http://asean.org/storage/2012/05/ASAPCP-UPLOADING11Nov16-Final.pdf [7 March 2021].

ASEAN Charter. (2008). Jakarta: ASEAN Secretariat.

ASEAN Community Vision 2025. (2015). ASEAN Socio-Cultural Community. Retrieved from https://www.asean.org/wp-content/uploads/images/2015/November/aecpage/ASEAN-Community-Vision-2025.pdf [7 March 2021].

Asia Toy \& Play Association. (2017). Toy Manufacturers Showcase Products in Thailand. ThaiPRnet.

https://www.atpa.asia/april-20-2017-toy-manufacturers-showcase-products-inthailand/

Bernama. (2018). 4,137 toys seized over non-compliance with safety standards. FMT News, https://www.freemalaysiatoday.com/category/nation/2018/03/21/4137-toysseized-over-non-compliance-with-safety-standards/ 
CNA. (2019). 10 magnetic toys found to be unsafe for children: Singapore product safety regulator. Channel News Asia.

https://www.channelnewsasia.com/news/singapore/magnetic-building-blocksballs-

buckyballs-toys-unsafe-children-11864290

CPSC US. (2013). Toy-Related Deaths and Injuries, Calendar Year. Retrieved from https://www.cpsc.gov/s3fs-public/pdfs/ToyReport2013.pdf [7 March 2021].

Decharat, S., Maneelo, S., \& Chuchay, S. (2013). Assessment of Lead Levels in some Children's Plastic Toys. KKU Res. J.18(3): 1026-1033.

Eurosafe. (2013). Injuries in the European Union, report on injury statistics 2008-2010. Retrieved from https://ec.europa.eu/health/sites/health/files/data_collection/docs/idb_report_201 3_en.pdf. [6 March 2021].

Fong, L. F. (2016). Health risk in household ware. The Star. https://www.thestar.com.my/news/nation/2016/07/09/health-risk-in-householdware-tests-on-ceramics-showed-over-10000-times-more-lead-than-allowed

Haniff, W. A. A. W., Ismail, R., Isa, S. M., Fadzil, R. M., AlSagoff, S. S., \& Khalid, T. K. A. (2019). Children's Toy Safety Standards in Malaysia And Asean: Towards Single Regional Regulation of Lead-Based Paints and Children Toys. International Journal of Asian Social Sciences, 10(9): 483-495.

Howells, G. G., \& Weatherill, S. (2005). Consumer Protection Law. England: Ashgate Publishing Ltd.

Ismail, R., Haniff, W. A. A. W., Isa, S. M., Fadzil, R. M., AlSagoff, S. S., \& Khalid, T. K. A. (2019). Asean Development On Children's Toy Safety. - The European Proceedings Of Social \& Behavioural Sciences. Pg 88-94.

Ismail, R., Haniff, W. A. A. W., Isa, S. M., Fadzil, R. M., AlSagoff, S. S., \& Khalid, T. K. A. (2020). Toy Safety in the ASEAN and European Union: A Comparative Approach. International Journal of Innovation, Creativity and Change, 10(11): 118-132.

Ismail, R., Haniff, W. A. A. W., Isa, S. M., Fadzil, R. M., AlSagoff, S. S., \& Khalid, T. K. A. (2019). The Approach to Safety of Children's Toys in United States and European Union: A Comparative Study. Academic Journal of Interdisciplinary Studies, 9(1): 126-136.

Ninety-Five Percent of Vietnam-Made Toys Exported. (2017). Thanh Nien News, Retrieved from https://www.seata.asia/may-20-2017-ninety-five-percent-ofvietnam-made-toys-exported/

NPD Group. (2018). Toy Sales Globally and in the U.S. Both Grow by 1 Percent in 2017, Reports the NPD Group. Retrieved from https://www.npd.com/wps/portal/npd/us/news/press-releases/2018/toy-salesglobally-and-in-the-us-both-grow-by-1-percent-in-2017-reports-the-npd-group/ [1 October 2019].

Statista. (2019). Total revenue of the global toy market from 2007 to 2018 . Retrieved from https://www.statista.com/statistics/194395/revenue-of-the-global-toy-marketsince-2007/ [1 October 2019].

Khalid, T. K. A. (2015). Kanak-kanak dan barang mainan. In Sakina, S.A., Ismail, R., \& Shamsuddin, S. (edts). Pengguna dan Undang-undang. Bangi: UKM Press. UN ESCAP. (2018). Complementarities between the ASEAN Community Vision 2025 and the 
United Nations 2030 Agenda for Sustainable Development: A Framework for Action. Retrieved from https://www.unescap.org/publications/complementarities-betweenasean-vision-2025-and-2030-agenda [7 March 2021].

United Nations. (2020). About the Sustainable Development Goals. Retrieved from https://www.un.org/sustainabledevelopment/sustainable-development-goals/ [7 March 2021].

Uyen, T. (2017). Chất độc Phthalate sẽ bị 'quản chặt' trong đồ chơi trẻ em. Thoibao.today. https://thoibaotoday.info/paper/chat-doc-phthalate-se-bi-quanchat-trong-do-choi-tre-em-2632431 